\title{
Papilionoideae (Leguminosae) nos campos ferruginosos do Parque Estadual do Itacolomi, Minas Gerais, Brasil: florística e fenologia ${ }^{1}$
}

\author{
VALQUÍRIA F. DUTRA ${ }^{2,4}$, MARIA CRISTINA T.B. MESSIAS ${ }^{3}$ e FLÁVIA CRISTINA P. GARCIA ${ }^{2}$
}

(recebido: 17 de junho de 2004; aceito: 5 de maio de 2005)

\begin{abstract}
Papilionoideae (Leguminosae) of "campos ferruginosos" of Itacolomi State Park, Minas Gerais, Brazil). A floristic survey of Papilionoideae species was carried out in "campos ferruginosos" of Itacolomy State Park (PEI), situated between Ouro Preto and Mariana cities, Minas Gerais. The collections was made from March, 2001 to May, 2002. Twenty species of 13 genera of Papilionoideae were identified. The genera that had more representative number of species were Desmodium (4), Crotalaria (3), Machaerium (2) and Stylosanthes (2). The others had only one specie each. In the phenological study of the species, correlations between environmental parameters (temperature and rainfall) and the leaf fall, leaf flushing, flowering and the fruiting were verified.
\end{abstract}

Key words - “campos ferruginosos”, floristic, Itacolomi State Park, Leguminosae-Papilionoideae, phenology

RESUMO - (Papilionoideae (Leguminosae) dos campos ferruginosos do Parque Estadual do Itacolomi, MG). Foi realizado um levantamento florístico das espécies de Papilionoideae (Leguminosae) ocorrentes nos campos ferruginosos do Parque Estadual do Itacolomi (PEI), situado nos municípios de Ouro Preto e Mariana, estado de Minas Gerais. As coletas foram feitas no período de março de 2001 a maio de 2002. Foram identificadas 20 espécies de Papilionoideae, pertencentes a 13 gêneros. Os gêneros mais representativos em número de espécies foram Desmodium (4), Crotalaria (3), Machaerium e Stylosanthes, com duas espécies cada. Os demais gêneros foram representados por apenas uma espécie cada. No estudo fenológico das espécies, foram constatadas correlações entre fatores climáticos (temperatura e precipitação) e a perda de folhas, brotação, floração e frutificação.

Palavras-chave - campos ferruginosos, fenologia, florística, Leguminosae-Papilionoideae, Parque Estadual do Itacolomi

\section{Introdução}

A família Leguminosae está representada por cerca de 650 gêneros e 18.000 espécies, distribuídas em florestas tropicais até desertos quentes; está subdividida em três subfamílias: Caesalpinioideae, Mimosoideae e Papilionoideae, sendo esta última a mais diversa e derivada, com aproximadamente 482 gêneros e 12.000 espécies (Polhill 1981). Lima (2000) mencionou para o Brasil 2.100 espécies nativas reunidas em 188 gêneros, distribuídos por diversos ecossistemas brasileiros, como mata atlântica, cerrado, caatinga e floresta amazônica.

O Estado de Minas Gerais apresenta grande variedade topográfica, geomorfológica, edáfica e climática, o que reflete uma rica variedade de formações

1. Parte da monografia de conclusão de curso da primeira autora, desenvolvida na Universidade Federal de Ouro Preto.

2. Universidade Federal de Viçosa, Departamento de Biologia Vegetal, Av. P.H. Rolfs s.n., 36570-000 Viçosa, MG, Brasil.

3. Universidade Federal de Ouro Preto, Instituto de Ciências Exatas e Biológicas, Departamento de Ciências Biológicas, Campus Morro do Cruzeiro, 35400-000 Ouro Preto, MG, Brasil.

4. Autora para correspondência: valdutra2@yahoo.com.br vegetacionais, reunidas em três grandes biomas: a mata atlântica, o cerrado e a caatinga, cada um deles com um grande número de fisionomias, como floresta ombrófila densa, floresta estacional semidecidual, campo-limpo, campo-cerrado, cerradão e campo rupestre (Araújo 2000).

O campo rupestre ocorre na Cadeia do Espinhaço, em áreas acima de $900 \mathrm{~m}$, ocupando uma área de aproximadamente $1.000 \mathrm{~km}$ de comprimento por 50 a $100 \mathrm{~km}$ de largura, desde a Serra de Ouro Branco, em Minas Gerais, até a Bahia (Giulietti \& Pirani 1988), onde recebe a denominação de Chapada Diamantina (Giulietti et al. 1987); e em áreas disjuntas em Goiás, no Distrito Federal, e na porção sudoeste e sul de Minas Gerais, como ilhas florísticas isoladas (Romero 2002), correspondendo a $3 \%$ da vegetação deste estado.

Devido ao alto grau de endemismo, o grande número de plantas ainda não conhecidas e a diversidade de microambientes (Zappi et al. 2002), as áreas de campos rupestres possuem importância ecológica de valor muito alto a extremo (Costa et al. 1998).

O Parque Estadual do Itacolomi (PEI) está situado no extremo oeste dos domínios da mata atlântica, na zona de transição com o cerrado, compondo o limite sul da Cadeia do Espinhaço. Sua vegetação é composta 
por floresta estacional semidecidual, floresta de galeria e campo rupestre, este com as fitofisionomias de campos quartzíticos e campos ferruginosos (Messias et al. 1997). Os campos ferruginosos ocupam porção significativa da vegetação campestre do Parque, em áreas com altitude em torno de 1.200 a $1.450 \mathrm{~m}$, encontram-se sobre a canga, concreções de sesquióxido de ferro e alumínio, que possui fendas por onde penetram as raízes dos vegetais, possibilitando assim, o desenvolvimento da vegetação (Messias et al. 1997). Segundo Vicent et al. (2002), os campos ferruginosos ocorrem principalmente no Quadrilátero Ferrífero (MG), mas, também, na Serra dos Carajás (PA), em regiões elevadas (acima de $1.000 \mathrm{~m}$ ) apresentando uma vegetação herbácea ou arbustiva pouco desenvolvida e bastante peculiar, porém, segundo Rizzini (1997), mais pobre floristicamente que os campos quartzíticos.

Mesmo após 35 anos da criação do PEI, a composição florística de seus tipos vegetacionais ainda é pouco conhecida (Messias et al. 1997). A alta representatividade da família Leguminosae nos campos rupestres, constatada por Garcia \& Dutra (2004), com 338 espécies e 52 gêneros, somada ao seu valor econômico e ecológico, confere grande importância ao conhecimento desta dentro desse tipo vegetacional.

Os estudos fenológicos são importantes para a compreensão da complexa dinâmica dos ecossistemas (Fournier 1976), porém são escassos em Leguminosae, restringindo-se aos de Mendonça Filho (1995), Bulhão \& Figueiredo (2002), Felfili et al. (1999) e Madeira \& Fernandes (1999), sendo este o único realizado em campos rupestres.

No presente estudo são apresentadas diagnoses, chaves para a identificação das espécies e os padrões fenológicos de Papilionoideae, ocorrentes nos campos ferruginosos do PEI.

\section{Material e métodos}

Área de estudo - O Parque Estadual do Itacolomi (PEI) está situado nos municípios de Ouro Preto e Mariana, Estado de Minas Gerais, entre os paralelos $20^{\circ} 22^{\prime} 30^{\prime \prime}$ e $20^{\circ} 30^{\prime} 00^{\prime \prime} \mathrm{S}$ e os meridianos de $43^{\circ} 32^{\prime} 30^{\prime \prime}$ e $43^{\circ} 22^{\prime} 30^{\prime \prime} \mathrm{W}$, abrangendo a maior parte da Serra do Itacolomi (Peron 1989). Ocupa uma área de aproximadamente 7.000 ha, sendo o ponto mais elevado o Pico do Itacolomi, com 1.772 m.s.m. Os campos rupestres do PEI abrangem toda a área acima da cota de 1.200 m.s.m., onde ocorrem os campos ferruginosos e os campos quartzíticos, com cinco tipos básicos de formações vegetacionais, segundo Peron (1989): capões de mata que acompanham os cursos d'água, capões de mata das encostas secas, campos graminosos secos, graminosos úmidos e dos afloramentos rochosos quartzíticos.

O clima na área, segundo a classificação de Koeppen, é do tipo Cwb, úmido (mesotérmico), ou seja, temperado úmido com inverno seco e verão quente e chuvoso. No período de estudo, a temperatura média mais baixa foi de $14,8^{\circ} \mathrm{C}$ e a mais alta, $24,1^{\circ} \mathrm{C}$. As precipitações mais baixas, inferiores a $3 \mathrm{~mm}$, ocorreram nos meses de junho e julho de 2001, e as mais altas, entre 260 e $330 \mathrm{~mm}$, de novembro de 2001 a fevereiro de 2002.

Coleta e tratamento do material botânico - O levantamento florístico foi realizado de março de 2001 a maio de 2002, através de visitas mensais ao campo. As coleções foram depositadas no Herbário Prof. José Badini (OUPR), da Universidade Federal de Ouro Preto, Minas Gerais e duplicatas foram doadas aos herbários ICN e VIC. A identificação do material botânico foi realizada através de literatura especializada, consulta a especialistas e por comparação com as coleções dos herbários $\mathrm{BHCB}, \mathrm{RB}$ e VIC.

A nomenclatura morfológica adotada nas diagnoses foi baseada nos trabalhos de Radford et al. (1974) e Polhill (1981) e, para frutos, Barroso et al. (1999). Os nomes dos autores das espécies foram abreviados de acordo com Brumitt \& Powell (1992).

Foram elaboradas uma chave dicotômica e diagnoses para identificação das espécies com base nos caracteres morfológicos observados nos espécimes coletados e, quando necessário, foram complementadas com materiais do herbário OUPR.

Acompanhamento fenológico - As observações fenológicas foram realizadas de março de 2001 a maio de 2002. Os indivíduos foram marcados e numerados determinando-se, mensalmente, a brotação (período de aparecimento de brotos foliares até a expansão das folhas novas); queda foliar (período de perda foliar); floração (período de produção de botões e de flores abertas); frutificação (período de produção de frutos jovens e maduros).

A análise qualitativa das estratégias de floração foi realizada de acordo com os padrões de Newstron et al. (1994) em: contínua, floração ao longo do ano, com breve ou nenhuma interrupção; anual explosiva, floração menor do que um mês; anual sazonal, floração de um a quatro meses; anual longa, floração de mais de quatro meses; e supra-anual, menos de um ciclo de floração por ano. Quanto ao período de frutificação, as espécies foram agrupadas em três categorias definidas, segundo Mendonça Filho (1995): frutificação longa, dez ou mais meses; frutificação intermediária, quatro a nove meses; e frutificação curta, até três meses. Também foram observadas as diferentes síndromes de dispersão dos diásporos, por meio da análise morfológica dos frutos e sementes, e de observações no campo, baseando-se na classificação de van der Pijl (1972) em anemocórica, zoocórica e autocórica.

A influência dos fatores climáticos na fenologia das espécies foi investigada através do coeficiente de correlação 
de Pearson (r) (Brussab \& Morettin 1986) entre a freqüência de ocorrência das fenofases e os elementos do clima.

\section{Resultados e Discussão}

Levantamento florístico - Foram encontradas 20 espécies de Papilionoideae nos campos ferruginosos do PEI, reunidas em 13 gêneros, sendo os mais representativos Desmodium (4 spp.), Crotalaria (3), Machaerium (2) e Stylosanthes (2), e os demais gêneros: Aeschynomene, Calopogonium, Camptosema, Centrosema, Dalbergia, Indigofera, Periandra, Vigna e Zornia, com uma espécie cada.

As tribos mais significativas, considerando o sistema de Polhill (1994), foram Phaseoleae, com cinco gêneros,
Aeschynomeneae, com três, e Dalbergieae, com dois; as demais (Crotalarieae, Desmodieae e Indigofereae) apresentaram apenas um gênero cada.

Muitas das espécies encontradas nos campos ferruginosos do PEI são comuns à Serra da Piedade (Brandão \& Gavilanes 1990), Barão de Cocais (Brandão \& Silva Filho 1993) e Antônio Pereira (Roschel 2000), outras áreas de campos ferruginosos da região. São elas: Stylosanthes viscosa e Zornia reticulata, que ocorrem no PEI, Serra da Piedade e Antônio Pereira; Camptosema scarlatinum, encontrada no PEI e Barão de Cocais; Aeschynomene elegans comum ao PEI e Serra da Piedade; e Periandra mediterranea, comum às quatro áreas. Entre essas localidades, o maior número de espécies foi encontrado nos campos ferruginosos do PEI.

Chave para as espécies de Papilionoideae ocorrentes nos campos ferruginosos do PEI

1. Arbustos

2. Ramos aculeados

15. Machaerium hirtum

2. Ramos inermes

3. Folhas trifolioladas

4. Folhas pecioladas; corola amarela

5. Ramos viscoso-hirsutos; folíolos tomentosos na face adaxial; anteras uniformes 18. Stylosanthes viscosa

5. Ramos tomentosos ou seríceos; folíolos glabros na face adaxial; anteras dimórficas

6. Folíolos 3,5-6,5 cm compr., lanceolados 6. Crotalaria micans

6. Folíolos 1-2 cm compr., obovados

5. Crotalaria incana

4. Folhas sésseis; corola lilás 16. Periandra mediterranea

3. Folhas pinadas

7. Folhas 7-11-folioladas

14. Machaerium brasiliense

7. Folhas 13-17-folioladas

8. Folíolos glabros na face adaxial e com tricomas malpiguiáceos na face abaxial; inflorescência em racemo; legume 13. Indigofera suffruticosa

8. Folíolos com ambas as faces seríceas; inflorescência em panícula; legume samaróide

1. Ervas ou trepadeiras

9. Ervas

10. Folhas uni ou bifolioladas

11. Folhas unifolioladas; inflorescência em racemo; legume inflado 7. Crotalaria nitens

11. Folhas bifolioladas; inflorescência em espiga; lomento 20. Zornia reticulata

10. Folhas pinadas ou trifolioladas

12. Folhas pinadas, 9-11-folioladas, estames diadelfos $(5+5)$ 1. Aeschynomene elegans

12. Folhas trifolioladas, estames monadelfos ou diadelfos $(9+1)$

13. Ramos vilosos a glabros; inflorescência em espiga; corola amarela

17. Stylosanthes montevidensis

13. Ramos tomentosos, uncinado-hirsutos ou uncinado-pubérulos; inflorescência em racemo; corola rósea

14. Folíolos obovados a obcordiformes, $0,5-1,1 \mathrm{~cm}$ 9. Desmodium adscendens 14. Folíolos elípticos, oblongos ou ovados, $1,2-5,7 \mathrm{~cm}$ 
15. Folíolos elípticos ou oblongos

11. Desmodium incanum

15. Folíolos ovados

16. Ramos uncinado-pubérulos

10. Desmodium affine

16. Ramos uncinado-hirsutos, viscosos

12. Desmodium uncinatum

9. Trepadeiras

17. Folíolos glabros em ambas as faces; inflorescência 1-4-flora; legume glabro

18. Ramos setosos; alas menores que o vexilo; pétalas da carena curvadas; legume achatado

4. Centrosema virginianum

18. Ramos glabros; alas de comprimento semelhante ao vexilo; pétalas da carena enroladas; legume cilíndrico 19. Vigna peduncularis

17. Folíolos hirsutos ou tomentosos, em pelo menos uma das faces; inflorescência multiflora; legume hirsuto ou viloso

19. Folíolos ovados ou rômbicos, hirsutos em ambas as faces; corola azul-violácea

2. Calopogonium mucunoides

19. Folíolos elípticos, glabros na face adaxial, tomentosos na face abaxial; corola vermelha

3. Camptosema scarlatinum

1. Aeschynomene elegans Schltdl. \& Cham., Linnaea 5:583. 1830.

Nome vulgar: sensitiva-mansa (Pio-Corrêa 1984).

Erva prostrada, ramos cilíndricos, viscosos; folhas imparipinadas, pecioladas, 9-11-folioladas, folíolos 0,5-1,5 ×0,3-0,6 cm, obovados a oblongos, híspidos em ambas as faces; inflorescência em racemo, biflora; corola amarela; estames diadelfos (5+5), anteras uniformes; fruto lomento, 3-5-articulado, ca. 1,5 cm compr., pubérulo-uncinado.

A. elegans distribui-se do México até o Uruguai e Argentina (Brandão 1992a). No Brasil, ocorre nos estados da BA, MG, PE, RJ, RS, SC e SP (Fernandes 1996). Nos campos ferruginosos do PEI apresentou ampla ocorrência, sendo mais freqüente em locais úmidos e sombreados. É uma espécie próxima de A. falcata (Poir.) DC., da qual difere pela forma do folíolo e do legume.

Material examinado: BRASIL: MINAS GERAIS: Ouro Preto, Parque Estadual do Itacolomi, estrada de cima, 27-III-2001 (fl., fr.), V.F. Dutra 25 (OUPR, ICN); 23-X-2001 (fl.), V.F. Dutra \& M.C.T.B. Messias 93 (OUPR); 22-XI-2001 (fr.), M.C.T.B. Messias \& V.F. Dutra 542 (OUPR); 27-XI-2001 (fl., fr.), M.C.T.B. Messias \& V.F. Dutra 578 (OUPR); estrada de baixo, 18-X-2001 (fr.), V.F. Dutra 90 (OUPR).

2. Calopogonium mucunoides Desv., Ann. Sci. Nat. (Paris) 9:423. 1826.

Nomes-vulgares: jequirana, falso-oró, orelha-deonça (Carvalho-Okano \& Leitão Filho 1985).

Trepadeira, ramos cilíndricos, hirsutos, ferrugíneos; folhas trifolioladas, pecioladas, folíolos 4,5-6,5 ×3-5 cm, ovados ou rômbicos, hirsutos em ambas as faces; inflorescência em racemo, multiflora; corola azulviolácea; estames diadelfos $(9+1)$, anteras uniformes; fruto legume, 2-3 cm compr., reto ou falcado, hirsuto.

É predominantemente neotropical, estando difundida desde o sul do México ao nordeste da Argentina, ocorrendo, no Brasil, na região amazônica, estendendose pelos estados litorâneos até o Estado de São Paulo e, no interior, até Mato Grosso do Sul (Carvalho-Okano \& Leitão Filho 1985). Ocorre, nos campos ferruginosos do PEI, próximo à entrada do Parque (1.230 m.s.m.), em locais úmidos. Distingue-se das demais espécies brasileiras, pelo cálice campanulado com lacínios subulados (Carvalho-Okano \& Leitão Filho 1985).

Material examinado: BRASIL: MINAS GERAIS: Ouro Preto, Parque Estadual do Itacolomi, entrada do parque, 27-III-2001 (fl.), V.F. Dutra 32 (OUPR, VIC); 22-IV-2001 (fl., fr.), V.F. Dutra 47 (OUPR); 14-VI-2001 (fr.), V.F. Dutra 61 (OUPR).

3. Camptosema scarlatinum (Benth.) Burkart, Darwiniana 16(1-2):199. 1970.

Trepadeira, ramos cilíndricos, tomentosos; folhas trifolioladas, pecioladas, folíolos 5-8 x 1,5-2,5 cm, elípticos, glabros na face adaxial, tomentosos na face abaxial; inflorescência em racemo, multiflora; corola vermelha; estames pseudomonadelfos, anteras uniformes; fruto legume, 3-6 cm compr., viloso.

Espécie forrageira que ocorre desde Goiás e Mato Grosso até o norte do Rio Grande do Sul, em campos e orlas de mata (Burkart 1970). Sua população na área 
estudada ocorre entre 1.300 e 1.350 m.s.m., nos barrancos na beira da estrada.

Material examinado: BRASIL: MinAS GERAIS: Ouro Preto, Parque Estadual do Itacolomi, estrada de cima, 14-VI-2001 (fl.), V.F. Dutra 59 (OUPR); 23-X-2001 (fl.), V.F. Dutra \& M.C.T.B. Messias 512 (OUPR); 27-XI-2001 (fl., fr.), V.F. Dutra \& M.C.T.B. Messias 568 (OUPR).

4. Centrosema virginianum (L.) Benth., Comm. Legum. Gen. p.56. 1837.

Nome vulgar: feijão-do-mato (Pio-Corrêa 1984).

Trepadeira, ramos sulcados, setosos; folhas trifolioladas, pecioladas, folíolos $2-4 \times 0,6-1,3 \mathrm{~cm}$, oblongos a lanceolados, glabros em ambas as faces; inflorescência em racemo, 1-2-flora; corola azulviolácea, com guias de néctar alvos, alas menores que o vexilo, pétalas da carena curvadas; estames diadelfos $(9+1)$, anteras uniformes; fruto legume achatado, ca. 6,5-10 cm compr., longo-acuminado, com margens espessadas, glabros.

Ocorre nos estados da BA, CE, MG, PB, PE, PR, RJ, RS, SC e SP, em restinga, cerrado, caatinga, praia, locais úmidos ou secos, na sombra ou não, em solos argilosos ou arenosos (Barbosa-Fevereiro 1977). Nos campos ferruginosos do PEI, ocorre associada a Melinis minutiflora P. Beauv., Poaceae (capim gordura), a 1.230 m.s.m.

Material examinado: BRASIL: MINAS GERAIS: Ouro Preto, Parque Estadual do Itacolomi, entrada do parque, 27-III-2001 (fl., fr.), V.F. Dutra 31 (OUPR, ICN).

\section{Crotalaria incana L., Sp. Pl. 2:716. 1753.}

Nomes vulgares: xique-xique, purupaqui (Lorenzi 1991).

Arbusto ca. $1 \mathrm{~m}$ alt., ramos cilíndricos, tomentosos; folhas trifolioladas, pecioladas, folíolos 1-2 $\times 0,5-1,5 \mathrm{~cm}$, obovados, glabros na face adaxial, velutinos na face abaxial; inflorescência em racemo, multiflora; corola amarela; estames monadelfos, anteras dimórficas; fruto legume inflado, 3,5-4 cm compr., verde, híspido.

Distribui-se pelas regiões tropicais (Barroso 1964), ocorrendo, no Brasil, em AL, BA, CE, GO, MA, MS, MG, PA, PB, PE, PI, PR, RJ, RN, RS, SC e SP (Lorenzi 1991). Nos campos ferruginosos do PEI, é encontrada próximo à entrada do Parque, a 1.230 m.s.m.

Material examinado: BRASIL: MinAS GERAIS: Ouro Preto, Parque Estadual do Itacolomi, entrada do parque, 5-II-2002 (fl., fr.), V.F. Dutra 104 (OUPR).
6. Crotalaria micans Link, Enum. Hort. Berol. 2:228. 1822.

Nomes vulgares: guizo-de-cascavel, chocalho (Leitão Filho et al. 1975).

Arbusto 0,4-1,5 m alt., ramos estriados, seríceopilosos; folhas trifolioladas, pecioladas, folíolos 3,5-6,5 $\times 0,9-2 \mathrm{~cm}$, lanceolados, glabros na face adaxial, seríceos na face abaxial; inflorescência em racemo, multiflora; corola amarela, com guias de néctar castanhos; estames monadelfos, anteras dimórficas; fruto legume inflado, $3 \mathrm{~cm}$ compr., castanho, glabrescente.

Ocorre em regiões tropicais e subtropicais (Barroso 1964), sendo encontrada, no Brasil, nos estados de AL, BA, CE, ES, GO, MG, MS, PB, PE, PI, PR, RJ, RN, RS, SC, SP e SE (Leitão Filho et al. 1975). É freqüentemente encontrada nos campos ferruginosos do PEI, a 1.230 m.s.m., associada principalmente a gramíneas.

Material examinado: BRASIL: MINAS GeRAIS: Ouro Preto, Parque Estadual do Itacolomi, estrada de baixo, 6-V-2001 (fl., fr.), V.F. Dutra 53 (OUPR, VIC).

7. Crotalaria nitens Kunth, Nov. Gen. Sp. 6:399-400. 1823 [1824].

Nome vulgar: xique-xique (Pio-Corrêa 1984).

Erva, ramos cilíndricos, hirsutos; folhas unifolioladas, pecioladas, folíolos 2,2-6 × 1,5-2 cm, elípticos a oblongos, ambas as faces seríceas; inflorescência em racemo, multiflora; corola amarela, com guias de néctar negros; estames monadelfos, anteras dimórficas; fruto legume inflado, $1,5-3 \mathrm{~cm}$ compr., glabro, negro quando maduro.

Ocorre na América Central e América do Sul (Polhill 2004). No Brasil, é citada para os estados do Amazonas e Minas Gerais (Pio-Corrêa 1984). Na área estudada sua população localiza-se, entre 1.315 a 1.435 m.s.m., em locais sombrios e úmidos.

Material examinado: BRASIL: MinAs GERAIS: Ouro Preto, Parque Estadual do Itacolomi, estrada de cima: 27-III-2001 (fl., fr.), V.F. Dutra 24 (OUPR, ICN); 14-VI-2001 (fr.), V.F. Dutra 57 (OUPR); estrada de baixo, 19-III-2001 (fl.), V.F. Dutra s.n. (OUPR 13.814); 6-V-2001 (fl.), V.F. Dutra s.n. (OUPR 13.815).

8. Dalbergia villosa (Benth.) Benth., J. Linn. Soc., Bot. 4 (suppl.):38. 1860.

Nomes vulgares: jacarandá, caviúna (Lorenzi 1992). Arbustos ca. $3 \mathrm{~m}$ alt.; ramos cilíndricos, vilosos; 
folhas imparipinadas, pecioladas, 15-17-folioladas, folíolos 1,5-2,7×0,4-0,9 cm, oblongos, discolores, ambas as faces seríceas; inflorescência em panícula, multiflora; corola amarelo-clara; estames monadelfos, anteras uniformes; fruto legume samaróide, ca. $5 \mathrm{~cm}$ compr., glabra, com região seminífera central.

D. villosa ocorre no Brasil Central, nos Estados de Minas Gerais e São Paulo, em áreas de cerrado (Carvalho 1997). É abundante na área estudada ocorrendo em todas as altitudes.

Material examinado: BRASIL: MINAS GERAIS: Ouro Preto, Parque Estadual do Itacolomi, estrada de cima, 27-III-2001 (fl., fr.), V.F. Dutra 23 (OUPR, ICN); 22-XI-2001 (fr.), V.F. Dutra \& M.C.T.B. Messias 536 (OUPR).

9. Desmodium adscendens (Sw.) DC., Prod. 2:332. 1825.

Nomes vulgares: carrapicho-beiço-de-boi, pegapega (Azevedo 1981).

Erva prostrada, ramos cilíndricos, tomentosos; folhas trifolioladas, pecioladas, folíolos $0,5-1,1 \times$ 0,3-0,8 cm compr., obovados a obcordiformes, face adaxial serícea, face abaxial serícea a glabra; inflorescência em racemo, multiflora; corola rósea; estames diadelfos $(9+1)$, anteras uniformes; fruto lomento, 1-3-articulado, 0,6-1,4 cm compr., uncinadopubérulo.

É uma espécie pouco exigente quanto ao tipo de hábitat, crescendo em solo arenoso ou argiloso, seco ou úmido, ensolarado ou sombrio, ocorrendo nos estados do AC, AM, BA, MG, MT, PA, PR, RJ, RS, SC e SP (Azevedo 1981). É encontrada em toda a área de campo ferruginoso do PEI. É de fácil reconhecimento, devido a forma característica de seus folíolos (Azevedo 1981). Assemelha-se, vegetativamente, a D. barbatum (L.) Benth., encontrada nos campos quartzíticos do PEI, mas esta última apresenta a inflorescência curta e densa. No PEI, as espécies de Desmodium apresentam caracteres reprodutivos muito similares, sendo que a morfologia foliar é o principal caráter que as diferencia.

Material examinado: BRASIL: MinAs GeRAIS: Ouro Preto, Parque Estadual do Itacolomi, estrada para a torre, 27-III-2001 (fl.), V.F. Dutra s.n. (OUPR12.127); estrada de baixo, 6-V-2001 (fl., fr.), V.F. Dutra 54 (OUPR); estrada de cima, 14-VI-2001 (fl.), V.F. Dutra 62 (OUPR).

10. Desmodium affine Schltdl., Linnaea 12:312. 1838.

Nomes vulgares: carrapicho, amores-do-campo- sujo, pega-pega (Azevedo 1981).

Erva prostrada, ramos estriados, uncinadopubérulos; folhas trifolioladas, pecioladas, folíolos 1,2-3,6 $\times 0,8-3 \mathrm{~cm}$, ovados, ambas as faces seríceas, glaucas; inflorescência em racemo, multiflora; corola rósea, estames diadelfos $(9+1)$, anteras uniformes; fruto lomento, 3-8-articulado, $5 \mathrm{~cm}$ compr., uncinado-pubérulo.

Distribui-se pelos estados da BA, CE, MA, MG, PA, PR, RJ, RS, SC e SP, principalmente em matas, mas também em campos, capoeiras, cerrados, capões, pastagens e campos rupestres (Azevedo 1981). É encontrada em toda a área de campo ferruginoso do PEI. Assemelha-se, vegetativamente, a $D$. subsericeum Malme e D. axillare (Sw.) DC., se distinguido das mesmas pela forma dos artículos do lomento e indumento do folíolo (Azevedo 1981).

Material examinado: BRASIL: Minas GeraIs: Ouro Preto, Parque Estadual do Itacolomi, Fazenda do Manso, 27-III-2001 (fl., fr.), V.F. Dutra 29 (OUPR).

\section{Desmodium incanum DC., Prodr. 2:332. 1825.}

Nomes vulgares: pega-pega, barba-de-boi (Azevedo 1981).

Erva ereta, ramos estriados, uncinado-pubérulos; folhas trifolioladas, pecioladas, folíolos 2,3-5,7 $\times$ 0,8-2,6 cm, elípticos ou oblongos, face adaxial serícea, face abaxial vilosa; inflorescência em racemo, multiflora; corola rósea; estames diadelfos $(9+1)$, anteras uniformes; fruto lomento, 2-6-articulado, 1,5-2,6 cm compr., uncinado-hirsuto.

Ocorre em vários tipos de ambientes, em locais sombreados ou ensolarados, em diferentes tipos de solos, dispersa por todo o Brasil (Azevedo 1981). É encontrada, nos campos ferruginosos do PEI, entre 1.230 e 1.260 m.s.m. Segundo Azevedo (1981), é muito difundida e polimorfa.

Material examinado: BRASIL: MinAs GERAIS: Ouro Preto, Parque Estadual do Itacolomi, entre estrada de cima e estrada de baixo para Fazenda do Manso, 1-IV-2001 (fl., fr.), V.F. Dutra s.n. (OUPR12.141).

12. Desmodium uncinatum (Jacq.) DC., Prodr. 2:331. 1825.

Nomes vulgares: carrapicho, pega-pega (Azevedo 1981).

Erva prostrada, ramos estriados, uncinado-hirsutos, viscosos, castanho-alaranjados; folhas trifolioladas, pecioladas, folíolos 2,5-5 × 0,9-2,1 cm, ovados, face adaxial verde-escura, serícea, geralmente com uma mácula glauca acompanhando a nervura central, face 
abaxial velutina; inflorescência em racemo, multiflora; corola rósea; estames diadelfos $(9+1)$, anteras uniformes; fruto lomento, 4-8-articulado, ca. $3,5 \mathrm{~cm}$ compr., uncinado-hirsuto.

Habita cerrado, restinga, campo rupestre, mata, pastagem, capoeira e em lugares úmidos, nos estados da BA, MG, PR, RJ, SC e SP, sendo referida como ruderal e invasora (Azevedo 1981). Nos campos ferruginosos do PEI, ocorre entre 1.315 e 1.435 m.s.m., em locais sombreados.

Material examinado: BRASIL: MinAS GERAIS: Ouro Preto, Parque Estadual do Itacolomi, estrada de baixo: 27-III-2001 (fl., fr.), V.F. Dutra 20 (OUPR, VIC); 6-V-2001 (fr.), V.F. Dutra 55 (OUPR).

13. Indigofera suffruticosa Mill., Gard. Dict. (ed. 8) Indigofera n. 2. 1768.

Nomes vulgares: anileira, indigueira, anileiraverdadeira (Pio-Corrêa 1984).

Arbusto ca. 2 m alt., ramos estriados, tomentosos; folhas imparipinadas, pecioladas, 13-15-folioladas, folíolos 1,2-2 × 0,5-0,9 cm, glabros na face adaxial, com tricomas malpiguiáceos na face abaxial; inflorescência em racemo, multiflora; corola rosa; estames diadelfos $(9+1)$, anteras uniformes, apiculadas; fruto legume curvado, 1,5-2 cm compr., seríceo.

I. suffruticosa possui ampla distribuição do norte ao sul do Brasil (Lewis 1987, Moreira \& Tozzi 1997), sendo freqüente na entrada do PEI. Assemelha-se, vegetativamente, a $I$. truxillensis Kunth, sendo esta diferenciada pelos tricomas malpiguiáceos em ambas as faces dos folíolos e pelos frutos retos (Moreira \& Tozzi 1997).

Material examinado: BRASIL: MINAS GERAIS: Ouro Preto, Parque Estadual do Itacolomi, entrada do parque, 27-III-2001 (fl., fr.), V.F. Dutra s.n. (OUPR12.124).

14. Machaerium brasiliense Vogel, Linnaea 11:185. 1837.

Nomes vulgares: pau-sangue, jacarandá, canelado-brejo (Lorenzi 1998).

Arbusto ca. $2 \mathrm{~m}$ alt., ramos cilíndricos, vilosos; folhas imparipinadas, pecioladas, 7-11-folioladas, folíolos alternos, 2,5-5,6 × 0,9-2 cm, elípticos a ovados, glabros em ambas as faces; inflorescência em racemo, multiflora; corola lilás; estames diadelfos $(9+1)$, anteras uniformes; fruto sâmara, 4,5-8 cm compr., glabra, com região seminífera basal.

Ocorre, como uma árvore, em mata mesófila semidecídua, mata ciliar e cerradão, nos Estados de São
Paulo e Minas Gerais (Mendonça Filho 1996, Sartori \& Tozzi 1998). Na área estudada, ocorre acima de 1.300 m.s.m. Difere-se de M. triste Vogel, espécie mais próxima, pelas flores pediceladas e hábito arbóreo (Sartori \& Tozzi 1998).

Material examinado: BRASIL: MinAs GeRAIs: Ouro Preto, Antônio Pereira, 10-XI-1997 (fl.), M.B. Roschel s.n. (OUPR8.662); Parque Estadual do Itacolomi, estrada de cima, 23-X-2001 (fr.), V.F. Dutra \& M.C.T.B. Messias 497 (OUPR).

15. Machaerium hirtum (Vell.) Stellfeld, Tribuna Farm. 12:132.1944.

Nomes vulgares: jacarandá-bico-de-pato, espinheiro (Lorenzi 1998).

Arbusto ca. 3,5 m alt., ramos aculeados, estrigosos, ferrugíneos; folhas imparipinadas, pecioladas, 15-19-folioladas, folíolos 1,2-2,7 × 0,5-0,8 cm, linearoblongos, ambas as faces pubescentes, discolores; inflorescência em racemo, multiflora; corola violácea; estames monadelfos, anteras uniformes; fruto sâmara, ca. $5 \mathrm{~cm}$ compr., glabra, com região seminífera basal.

Ocorre nos Estados do Rio de Janeiro, Minas Gerais e São Paulo (Lima 1995, Mendonça Filho 1996, Sartori \& Tozzi 1998). É encontrada, freqüentemente, próximo à entrada do PEI. Caracteriza-se pelos folíolos estreitooblongos, acúleos retilíneos e achatados e hábito sempre arbóreo, o que a distingue das espécies próximas, que são escandentes. No PEI, assemelha-se, vegetativamente, a $D$. villosa (Benth.) Benth., diferindo desta, principalmente, pela presença de acúleos nos ramos.

Material examinado: BRASIL: MINAS GERAIS: Ouro Preto, Taquaral, 23-I-1983 (fl.), J. Badini s.n. (OUPR13.696); 14-III-1984 (fl.), J. Badini s.n. (OUPR13.695), Parque Estadual do Itacolomi, estrada de baixo, 18-X-2001 (fr.), V.F. Dutra 116 (OUPR).

16. Periandra mediterranea (Vell.) Taub., Nat. Pflanzenfam. 3(3):359. 1894.

Nomes vulgares: alcaçuz-da-terra, pau-doce, raizdoce (Messias et al. 1997).

Arbusto 1-2 m alt., ramos cilíndricos, tomentosos; folhas trifolioladas, sésseis, folíolos 3-6,5 $\times 0,8-0,2 \mathrm{~cm}$, lanceolados ou linear-lanceolados, face adaxial glabra, face abaxial com nervuras pubérulas e seríceas; inflorescência em racemo, multiflora, congesta; corola lilás, com guias de néctar esbranquiçados; estames diadelfos $(9+1)$, anteras uniformes; fruto legume, 4-7,5 cm compr., pubérulo. 
Habita preferencialmente campos rupestres da Serra do Espinhaço (Minas Gerais e Bahia), Serra Dourada e Chapada dos Veadeiros (Goiás), estendendo-se pelos cerrados e regiões mistas da caatinga (Funch \& Barroso 1999). Nos campos ferruginosos do PEI, é freqüentemente encontrada nas encostas, entre 1.300 e 1.350 m.s.m. Segundo Funch \& Barroso (1999), exibe acentuado polimorfismo, tanto nos folíolos quanto no hábito.

Material examinado: BRASIL: MinAS GERAIS: Ouro Preto, Parque Estadual do Itacolomi, estrada de cima, 22-IV-2001 (fl., fr.), V.F. Dutra 50 (OUPR, VIC); 23-X-2001 (fr.), M.C.T.B. Messias et al. 516 (OUPR).

17. Stylosanthes montevidensis Vogel, Linnaea 12:67. 1838.

Nome vulgar: meladinho (Pio-Corrêa 1984).

Erva, ramos estriados, vilosos a glabros; folhas trifolioladas, pecioladas, folíolos 1,7-2,7 ×0,1-0,4 cm, lanceolados, ambas as faces glabras; inflorescência em espiga, multiflora; corola amarela; estames monadelfos, anteras uniformes; fruto lomento, 1-articulado, ca. $0,3 \mathrm{~cm}$ compr., glabro.

Ocorre na América Central, México, Bahamas, Cuba, Colômbia, Venezuela e Brasil, nos estados de GO, MG, MT, PR, RJ, RS, SC e SP (Mohlenbrock 1963, Brandão \& Costa 1979). Ocorre nos campos ferruginosos do PEI, entre 1.230 e 1.260 m.s.m., em ambientes sombreados.

Material examinado: BRASIL: MinAs GERAIS: Ouro Preto, Parque Estadual do Itacolomi, entre estrada de baixo e estrada de cima, 1-IV-2001 (fl.), V.F. Dutra 43 (OUPR, ICN); estrada de cima: 1-IV-2001 (fl., fr.), V.F. Dutra 38 (OUPR, VIC).

18. Stylosanthes viscosa Sw., Prodr. p.108. 1788.

Nomes vulgares: alfafa-do-campo, pitobi-da-praia (Pio-Corrêa 1984).

Arbusto ca. $40 \mathrm{~cm}$ alt., ramos cilíndricos, viscosohirsutos; folhas trifolioladas, pecioladas, folíolos 1,2-2,5 $\times$ 0,4-0,8 cm, elípticos a oblongos, ambas as faces tomentosas; inflorescência em espiga, multiflora; corola amarela; estames monadelfos, anteras uniformes; fruto lomento, 1-articulado, ca. 0,3 cm compr., glabro.

S. viscosa ocorre na América Central, Bahamas, Cuba, México e América do Sul (Mohlenbrock 1963). No Brasil, distribui-se pelos estados de AL, BA, CE, ES, MA, MG, MT, PA, PR, PE, RJ, RN, SC, SP e SE (Brandão \& Costa 1979, Brandão 1992b). Nos campos ferruginosos do PEI, é encontrada entre 1.230 e
1.350 m.s.m.

Material examinado: BRASIL: MINAS GERAIS: Ouro Preto, Parque Estadual do Itacolomi, estrada de cima, 1-IV-2001 (fl., fr.), V.F. Dutra 40 (OUPR); 1-IV-2001 (fl.), V.F. Dutra 37 (OUPR, ICN).

19. Vigna peduncularis (Kunth) Fawc. \& Rendle, Fl. Jamaica 4(2):68. 1920.

Nome vulgar: feijão-do-mato (Pio-Corrêa 1984).

Trepadeira, ramos estriados, glabros; folhas trifolioladas, pecioladas, folíolos 1,5-5 × 0,9-2,7 cm, lanceolados ou ovado-triangulares, glabros em ambas as faces; inflorescência em racemo, 2-4-flora; corola azul-violácea, alas de tamanho semelhante ao vexilo, pétalas da carena, gineceu e androceu enrolados; estames diadelfos $(9+1)$, anteras uniformes; fruto legume cilíndrico, ca. $10 \mathrm{~cm}$ compr., glabro.

Distribui-se da América Central ao norte da Argentina e, no Brasil, desde o AM até a BA, MG, GO e MT (Maréchal et al. 1978). Na área estudada, ocorre em barrancos úmidos, entre 1.260 e 1.400 m.s.m.

Material examinado: BRASIL: MINAS GERAIS: Ouro Preto, Parque Estadual do Itacolomi, estrada de baixo, 19-III-2001 (fl.), V.F. Dutra 35 (OUPR); 27-III-2001 (fl.), V.F. Dutra 36 (OUPR); estrada de cima, 22-IV-2001 (fl.), V.F. Dutra 51 (OUPR); 21-V-2001 (fl., fr.), V.F. Dutra 56 (OUPR); 22-XI-2001 (fr.), V.F. Dutra s.n. (OUPR 13.587).

20. Zornia reticulata Sm., Cycl. 39:Zornia n.2.1818.

Nomes vulgares: carrapicho, urinária, alfafa-docampo (Pio-Corrêa 1984).

Erva, ramos estriados, glabros; folhas bifolioladas, pecioladas, folíolos 1,9-5,5 × 0,3-1,1 cm, linearlanceolados, face adaxial glabra, face abaxial serícea; inflorescência em espiga, multiflora, congesta, bracteada; corola amarela; estames monadelfos, anteras dimórficas; fruto lomento, 3-6-articulado, ca. $1 \mathrm{~cm}$ compr., coberto por tricomas translúcidos.

Z. reticulata ocorre desde a Índia, sul dos Estados Unidos e América Central chegando até o Paraguai (Brandão 1996). Na área estudada, ocorre em barrancos úmidos, entre 1.260 e 1.400 m.s.m. Segundo Mohlembrock (1961), é a espécie mais definida e mais variável de Zornia.

Material examinado: BRASIL: MinAs GERAIS: Ouro Preto, Parque Estadual do Itacolomi, estrada de cima, 27-III-2001 (fl.), V.F. Dutra 26 (OUPR); 27-III-2001 (fl.), V.F. Dutra 27 (OUPR), 27-III-2001 (fr.), V.F. Dutra 28 (OUPR). 
Fenologia - O clima na região do PEI é sazonal, com duas estações bem definidas: uma seca e fria, de maio a setembro e outra quente e úmida, de outubro a abril. De acordo com os dados da tabela 1, observa-se que a fenologia vegetativa mostrou sazonalidade ligada ao clima. A queda das folhas ocorreu em $15 \%$ das espécies (Dalbergia villosa, Machaerium brasiliense e M. hirtum), nos meses de abril e maio, apresentando correlação negativa com a precipitação $(r=-0,259)$ e a temperatura $(\mathrm{r}=-0,716)$. Nesse período, ocorreu uma diminuição da pluviosidade e a queda das folhas pode representar uma adaptação vegetativa contra a perda de água (Rizzini 1997), aumentando a possibilidade de sobrevivência em plantas perenes (Salisbury \& Ross 1992), já que as anuais (50\% das espécies estudadas) morrem após a floração e frutificação, algumas vezes reduzindo a planta apenas ao seu sistema subterrâneo. Este padrão de queda foliar nos meses de menor taxa pluviométrica também foi encontrado por diversos autores, trabalhando em áreas de cerrado e florestas tropicais, como Barros \& Caldas (1980), Dutra (1987), Mantovani \& Martins (1988), Morellato et al. (1989), Morellato et al. (1990).

A brotação ocorreu em $70 \%$ das espécies, de setembro de 2001, final da estação seca, até abril de 2002, sendo o pico de brotação no mês de novembro de 2001, coincidindo com o período em que ocorreu aumento acentuado na precipitação média mensal $(\mathrm{r}=0,808)$. Um aspecto interessante observado, em Dalbergia villosa, foi o brotamento radicular, essa característica, segundo Rizzini \& Heringer (1966), é encontrada em muitas espécies, e deve-se a perturbações do ambiente que interferem na reprodução por semente e estimulam a emissão de gemas, como a ação do fogo, comum em campos rupestres.

A floração ocorreu durante todo o ano, sendo que a maior porcentagem de espécies florescendo ocorreu nos meses de março e abril de 2001 e março de 2002, em $70 \%$ das espécies (figura 1), havendo uma correlação positiva da floração com a temperatura $(r=0,613)$. Este

Tabela 1. Espécies de Papilionoideae dos campos ferruginosos do PEI e seus respectivos dados fenológicos, de março de 2001 a maio de 2002. $c o=$ floração contínua, ae = floração anual explosiva, as = floração anual sazonal, al = floração anual longa, $\mathrm{sa}=$ floração supra-anual, ane = dispersão anemocórica, zoo = dispersão zoocórica, aut $=$ dispersão autocórica.

Table 1. Papilionoideae species found in "campos ferruginosos" inside PEI and their respective phenological data, from March, 2001 to May, 2002. co = continuous flowering, ae = brief annual flowering, as = seasonal annual flowering, al $=$ extended annual flowering, $\mathrm{sa}=$ supra-annual flowering, ane $=$ anemochory, $\mathrm{zoo}=$ zoochory, aut $=$ autochory .

\begin{tabular}{lcccccc}
\hline Espécie & $\begin{array}{c}\text { Queda das } \\
\text { folhas }\end{array}$ & Brotação & Floração & Frutificação & $\begin{array}{c}\text { Estratégia de } \\
\text { floração }\end{array}$ & $\begin{array}{c}\text { Dispersão dos } \\
\text { diásporos }\end{array}$ \\
\hline Aeschynomene elegans & - & - & jul-abr & mar-nov & co & zoo \\
Calopogonium mucunoides & - & out-fev & mar-abr & abr-ago & as & aut \\
Camptosema scarlatinum & - & - & jun-nov & ago-dez & al & aut \\
Centrosema virginianum & - & fev-mar & mar-abr & mar-abr & as & aut \\
Crotalaria incana & - & set-nov & fev-abr & fev-ago & as & aut \\
Crotalaria micans & - & - & dez-ago & jan-ago & co & aut \\
Crotalaria nitens & - & set-nov & dez-jul & jan-ago & al & aut \\
Dalbergia villosa & abr-mai & nov-fev & mar & mar-nov & ae & ane \\
Desmodium adscendens & - & set-jan & jan-jun & fev-jun & al & zoo \\
Desmodium affine & - & set-jan & jan-abr & fev-mai & as & zoo \\
Desmodium incanum & - & set-jan & jan-abr & fev-mai & as & zoo \\
Desmodium uncinatum & - & set-jan & mar-abr & mar-mai & as & zoo \\
Indigofera suffruticosa & - & nov-dez & dez-abr & mar-ago & al & aut \\
Machaerium brasiliense & abr-mai & dez-abr & - & mar-out & sa & ane \\
Machaerium hirtum & abr-mai & - & - & mar-out & sa & ane \\
Periandra mediterranea & - & - & dez-jul & jan-out & al & aut \\
Stylosanthes montevidensis & - & dez-jan & mar-jul & mai-ago & al & aut \\
Stylosanthes viscosa & - & jan-fev & abr-jul & abr-ago & as & aut \\
Vigna peduncularis & - & - & jan-jan & jan-jan & co & aut \\
Zornia reticulata & - & out-nov & dez-jun & mar-jun & al & zoo \\
\hline
\end{tabular}




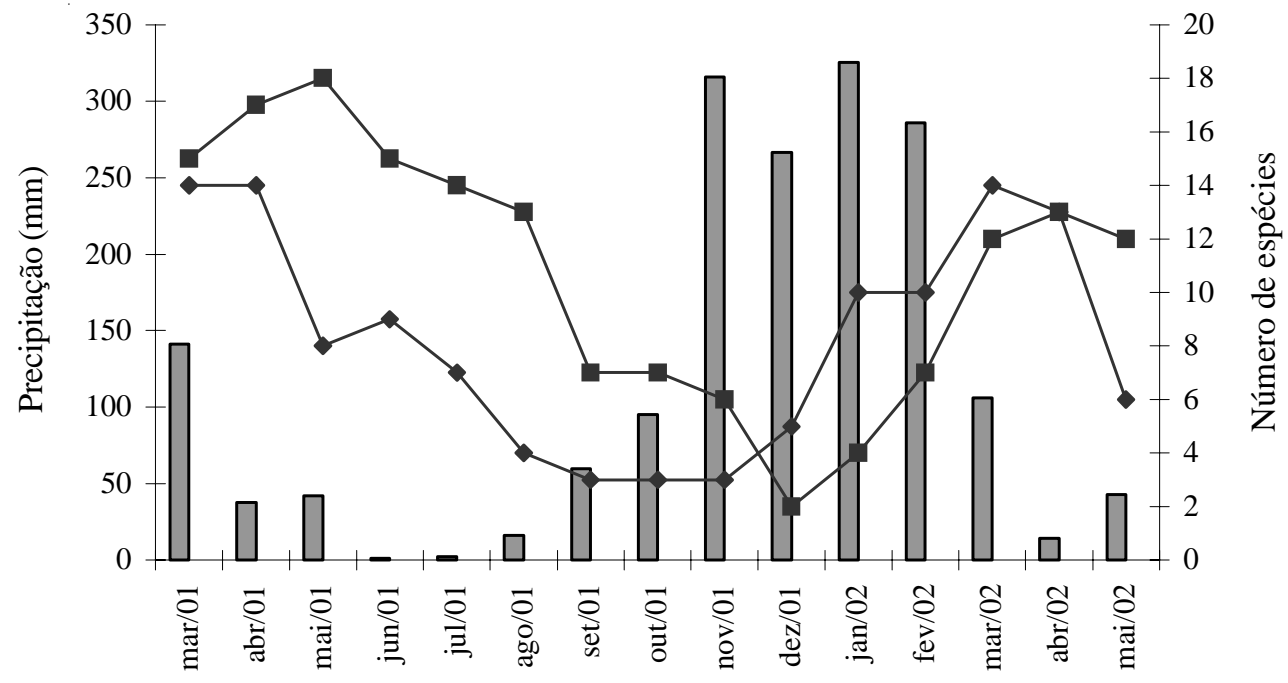

Figura 1. Periodicidade de floração e frutificação das espécies de Papilionoideae dos campos ferruginosos do PEI relacionados com a precipitação. $\square=$ precipitação; $-\mathbf{-}=$ floração; $-\mathbf{-}=$ frutificação.

Figure 1. Flowering and fruiting of the Papilionoideae species in "campos ferruginosos" found inside PEI in relation to rainfall. $\square=$ precipitation; $-\mathbf{-}=$ flowering; $-\boldsymbol{-}=$ frutification .

padrão concorda com os resultados obtidos por Barros \& Caldas (1980), Mantovani \& Martins (1988) e Mantovani et al. (2003), em áreas de cerrado e mata.

As espécies mostraram um padrão de floração anual (80\%), sendo 35\% de floração longa, $40 \%$ de sazonal e 5\%, explosiva, representada por Dalbergia villosa. A floração contínua, em Aeschynomene elegans e Vigna peduncularis, representou $10 \%$ do total das espécies e, apenas duas, não apresentaram floração, Machaerium brasiliense e Machaerium hirtum. Estas espécies apresentam floração supraanual, pois floresceram antes do início deste estudo, sendo coletadas somente com frutos.

Todas as espécies estudadas apresentaram frutos no período de observação, podendo-se observar que o período com maior número de espécies frutificando foi de março a agosto (figura1). A frutificação correlacionou-se negativamente com a precipitação $(\mathrm{r}=-0,768)$. Assim, à medida que a precipitação se reduziu, ocorreram as maiores porcentagens de espécies frutificando, resultado que se deu em função das espécies autocóricas (55\% do total das espécies), que apresentam legumes secos, e necessitam que seus frutos sofram desidratação do pericarpo, para ocorrer sua deiscência (Mantovani \& Martins 1988); e das anemocóricas (15\%), que apresentam sâmaras ou legumes samaróides, e que a queda das folhas e os ventos mais fortes favorecem a dispersão dos diásporos (Morellato et al. 1990). Batalha \& Mantovani (2000) também encontraram uma maior porcentagem de espécies autocóricas e anemocóricas, no extrato herbáceo da vegetação do cerrado, frutificando na estação seca.

A zoocoria esteve presente em $30 \%$ das espécies, que apresentam fruto do tipo lomento, típico das tribos Aeschynomeneae e Desmodieae, sendo a maioria cobertos por pêlos uncinados, que os tornam aptos à dispersão, aderidos ao corpo dos animais (Barroso et al. 1999).

A maioria (85\%) apresentou período de frutificação intermediário; Centrosema virginianum e Desmodium uncinatum apresentaram frutificação curta e Vigna peduncularis, longa. Segundo Mantovani \& Martins (1988), o período de floração influi na época da frutificação e tem um significado adaptativo na dispersão dos diásporos.

Este estudo revelou que as espécies de Papilionoideae encontradas nos campos ferruginosos do PEI são comuns a outras áreas de campos ferruginosos da região. As fenofases não apresentaram nenhuma relação com o hábito das espécies, mas se mostraram influenciadas pela ação conjunta dos fatores climáticos, associados às características morfológicas das espécies e dos fatores ecológicos, sendo verificada uma relação, entre a precipitação e a temperatura, positiva com a brotação, e negativa com a frutificação e queda das folhas.

Agradecimentos - Ao Programa de Iniciação Científica da Universidade Federal de Ouro Preto (PIP/UFOP) pela bolsa 
concedida à primeira autora e ao Instituto Estadual de Florestas/MG, em nome do Diretor do Parque Estadual do Itacolomi, Alberto Vieira de Mello Matos, pelo apoio e oportunidade de trabalho nesta Unidade de Conservação.

\section{Referências bibliográficas}

ARAÚJO, M.A.R. 2000. Conservação da biodiversidade em Minas Gerais: em busca de uma estratégia para o século XXI. Unicentro Newton Paiva, Belo Horizonte.

AZEVEDO, A.M.G. 1981. O gênero Desmodium Desv. no Brasil - considerações taxonômicas. Dissertação de mestrado, Universidade de Campinas, Campinas.

BARBOSA-FEVEREIRO, V.P. 1977. Centrosema (A.P. de Candolle) Bentham do Brasil - Leguminosae-Faboideae. Rodriguésia 42:159-219.

BARROS, M.A.G. \& CALDAS, L.S. 1980. Acompanhamento de eventos fenológicos apresentados por cinco gêneros nativos do cerrado (Brasília-DF). Brasil Florestal 42:7-14.

BARROSO, G.M. 1964. Leguminosas da Guanabara. Arquivos do Jardim Botânico do Rio de Janeiro 18:109-177.

BARROSO, G.M., MORIM, M.P., PEIXOTO, A.L. \& ICHASO, C.L.F. 1999. Frutos e sementes: morfologia aplicada à sistemática de dicotiledôneas. Imprensa Universitária, Viçosa.

BATALHA, M.A. \& MANTOVANI, W. 2000. Reproductive phenological patterns of cerrado plant species at the Pé-de-gigante Reserve (Santa Rita do Passa Quatro, SP, Brazil): a comparison between the herbaceous and woody floras. Revista Brasileira de Biologia 60:129-145.

BRANDÃO, M. 1992a. Gênero Aeschynomene L.: espécies mineiras e sua distribuição no país. Daphne 2:27-46.

BRANDÃO, M. 1992b. O gênero Stylosanthes no estado de Minas Gerais. Epamig, Belo Horizonte.

BRANDÃO, M. 1996. O gênero Zornia Gmell. no estado de Minas Gerais. Daphne 6:21-39.

BRANDÃO, M. \& COSTA, N.M.S. 1979. O gênero Stylosanthes Sw. no Brasil. Epamig, Belo Horizonte.

BRANDÃO, M. \& GAVILANES, M.L. 1990. Mais uma contribuição para o conhecimento da Cadeia do Espinhaço em Minas Gerais (Serra da Piedade) - II. Daphne 1:26-43.

BRANDÃO, M. \& SILVA FILHO, P.V. 1993. Os campos rupestres no município de Barão de Cocais, MG. Daphne 3:11-20.

BRUMMITT, R.K. \& POWELL, C.E. 1992. Authors of plant names. Royal Botanic Gardens, Kew.

BRUSSAB, W.O. \& MORETTIN, P.A. 1986. Estatística básica. Atual, São Paulo.

BULHÃO, C.F. \& FIGUEIREDO, P.S. 2002. Fenologia de leguminosas arbóreas em uma área de cerrado marginal no nordeste do Maranhão. Revista Brasileira de Botânica 25:361-369.

BURKART, A. 1970. Leguminosas-Faseóleas argentinas de los géneros Mucuna, Dioclea y Camptosema.
Darwiniana 16:175-218.

CARVALHO, A.M. 1997. A synopsis of the genus Dalbergia (Fabaceae, Dalbergieae) in Brazil. Brittonia 49:87-109.

CARVALHO-OKANO, R.M. \& LEITÃO FILHO, H.F. 1985. Revisão do gênero Calopogonium Desv. (LeguminosaeLotoideae) no Brasil. Revista Brasileira de Botânica 8:31-46.

COSTA, C.M.R, HERRMANN, G., MARTINS, G., LINS, L.V. \& LAMAS, I.R. 1998. Biodiversidade em Minas Gerais: um atlas para a sua conservação. Fundação Biodiversitas, Belo Horizonte.

DUTRA, R.C. 1987. Fenologia de dez espécies arbóreas nativas do cerrado de Brasília - DF. Brasil Florestal 62:23-28.

FELFILI, F.M., SILVAJÚNIOR, M.C., DIAS, B.J. \& REZENDE, A.V. 1999. Estudo fenológico de Stryphnodendron adstringens (Mart.) Coville no cerrado sensu stricto da Fazenda Água Limpa no Distrito Federal, Brasil. Revista Brasileira de Botânica 22:83-90.

FERNANDES, A. 1996. O táxon Aeschynomene no Brasil. Editora Universidade Federal do Ceará, Fortaleza.

FOURNIER, L.A. 1976. Observaciones fenologicas en el bosque húmedo de pre-montano de San Pedro de Montes de Oca, Costa Rica. Turrialba 26:54-59.

FUNCH, L.S. \& BARROSO, G.M. 1999. Revisão taxonômica do gênero Periandra Mart. ex Benth. (Leguminosae, Papilionoideae, Phaseoleae). Revista Brasileira de Botânica 22:539-564.

GARCIA, F.C.P. \& DUTRA, V.F. 2004. Leguminosae nos campos rupestres. CD-ROM (Simpósios, palestras e mesas redondas do $55^{\circ}$ Congresso Nacional de Botânica) Alpha Mídia Assessoria Fonográfica Ltda., Viçosa.

GIULIETTI, A.M. \& PIRANI, J.R. 1988. Patterns of geographic distribution of some plant species from the Espinhaço Range, Minas Gerais and Bahia, Brazil. In Proceedings of a Workshop on Neotropical Distribution Patterns (W.R. Heyer \& P.E. Vanzolini, eds.). Academia Brasileira de Ciências, Rio de Janeiro, p.39-69.

GIULIETTI, A.M., MENEZES, N.L., PIRANI, J.R., MEGURO, M. \& WANDERLEY, M.G.L. 1987. Flora da Serra do Cipó, Minas Gerais: Caracterização e lista das espécies. Boletim de Botânica da Universidade de São Paulo 9:1-151.

LEITÃO FILHO, H.F., ARANHA, C. \& BACCHI, O. 1975. Plantas invasoras de culturas no Estado de São Paulo. Hucitec, São Paulo, v. 2.

LEWIS, G.P. 1987. Legumes of Bahia. Royal Botanic Gardens, Kew.

LIMA, H.C. 1995. Leguminosas da Flora fluminensis - J. M. da C. Vellozo - lista atualizada das espécies arbóreas. Acta Botanica Brasilica 9:123-146.

LIMA, H.C. 2000. Leguminosas arbóreas da Mata Atlântica: uma análise da riqueza, padrões de distribuição geográfica e similaridades florísticas em remanescentes florestais do estado do Rio de Janeiro. Tese de doutorado, 
Universidade Federal do Rio de Janeiro, Rio de Janeiro.

LORENZI, H. 1991. Plantas Daninhas do Brasil: terrestres, aquáticas, parasitas, tóxicas e medicinais. Editora Plantarum, São Paulo, ed. 2.

LORENZI, H. 1992. Árvores brasileiras: manual de identificação e cultivo de plantas arbóreas nativas do Brasil. Editora Plantarum, São Paulo, v. 1.

LORENZI, H. 1998. Árvores brasileiras: manual de identificação e cultivo de plantas arbóreas nativas do Brasil. Editora Plantarum, São Paulo, v. 2.

MADEIRA, J.A. \& FERNANDES, G.W. 1999. Reproductive phenologhy of sympatric taxa of Chamaecrista (Leguminosae) in Serra do Cipó, Brazil. Journal of Tropical Ecology 15:463-479.

MANTOVANI, W. \& MARTINS, F.R. 1988. Variações fenológicas das espécies do cerrado da Reserva Biológica de Moji-Guaçu, Estado de São Paulo. Revista Brasileira de Botânica 11:101-112.

MANTOVANI, M., RUSCHEL, A.R., REIS, M.S., PUCHALSKI, A. \& NODARI, R.O. 2003. Fenologia reprodutiva de espécies arbóreas em uma formação secundária de floresta atlântica. Revista Árvore 27:451-458.

MARÉCHAL, R., MASCHERPA, J.M. \& STAINER, F. 1978. Étude taxonomique d'un groupe complex d'espéces des genres Phaseolus et Vigna (Papilionaceae) sur la base de données morphologiques et polliniques, traitées par l'analyse informatique. Boissiera 28:1-273.

MENDONÇA FILHO, C.V. 1995. Fenologia de Leguminosas arbóreas da Estação Biológica de Caratinga, Caratinga, MG. Dissertação de mestrado, Universidade Federal de Minas Gerais, Belo Horizonte.

MENDONÇAFILHO, C.V. 1996. Braúna, angico e jacarandá e outras leguminosas de mata atlântica: Estação Biológica de Caratinga, Minas Gerais. Fundação Biodiversitas/ Fundação Botânica Margaret Mee, Belo Horizonte.

MESSIAS, M.C.T.B., DIAS, S.J., ROSCHEL, M.B., SOUSA, H.C. \& MATOS, A.M. 1997. Levantamento florístico das matas e distribuição de algumas espécies endêmicas da área do Parque Estadual do Itacolomi. Relatório técnico UFOP/BIRD/IEF-PROFLORESTA, Universidade Federal de Ouro Preto, Ouro Preto.

MOHLENBROCK, R.H. 1961. A monograph of the Leguminosae genus Zornia. Webbia 16:1-141.

MOHLENBROCK, R.H. 1963. Further considerations in Stylosanthes (Leguminosae). Rhodora 65:245-258.

MOREIRA, J.L.A. \& TOZZI, A.M.G.A. 1997. Indigofera L. (Leguminosae, Papilionoideae) no estado de São Paulo, Brasil. Revista Brasileira de Botânica 20:97-117.

MORELLATO, L.P.C., RODRIGUES, R.R., LEITÃO FILHO, H.F. \& JOLY, C.A. 1989. Estudo comparativo da fenologia de espécies arbóreas de floresta de altitude e floresta mesófilo semidecídua na Serra do Japi, Jundiaí, São Paulo. Revista Brasileira de Botânica 12:85-98.

MORELLATO,L.P.C.,LEITÃO FILHO,H.F., RODRIGUES, R.R. \& JOLY, C.A. 1990. Estratégias fenológicas de espécies arbóreas em floresta de altitude na Serra do Japi, Jundiaí,
São Paulo. Revista Brasileira de Biologia 50:149-162.

NEWSTRON, L.E., FRANKIE, G.W. \& BAKER, H.G. 1994. A new classification for plant phenology based on flowering patterns in lowland tropical rain forest, Costa Rica. Biotropica 26:141-159.

PERON, M.V. 1989. Listagem preliminar da flora fanerogâmica dos Campos Rupestres do Parque Estadual do Itacolomi, Ouro Preto/Mariana, MG. Rodriguésia 67:63-69.

PIO-CORRÊA, M. 1984. Dicionário das plantas úteis do Brasil e das exóticas cultivadas. Imprensa Nacional, Rio de Janeiro, ed. 2, $6 \mathrm{v}$.

POLHILL, R.M. 1981. Papilionoideae. In Advances in Legume Systematics I (R.M. Polhill \& P.H. Raven, eds.) Royal Botanic Gardens, Kew, p.191-208.

POLHILL, R.M. 1994. Complete synopsis of legume genera. In Phytochemical dictionary of the Leguminosae (F.A. Bisby, J. Buckingham \& J.B. Harborne, eds.) Chapman and Hall, New York, v. 1, p. 49-54.

POLHILL, R.M. 2004. Crotalarieae. In International Legumes Database \& Information Service. http://www.ildis.org (acesso em 12/05/2004).

RADFORD, A.E., DICKISON, W.C., MASSEY, J.R. \& BELL, C.R. 1974. Vascular plant systematics. Harper \& Row, New York.

RIZZINI, C.T. 1997. Tratado de Fitogeografia do Brasil. HUCITEC/EDUSP, São Paulo.

RIZZINI, C.T. \& HERINGER, E.P. 1966. Estudo sobre os sistemas subterrâneos difusos de plantas campestres. Anais da Academia Brasileira de Ciências 38:85-112.

ROMERO, R. 2002. Diversidade da flora dos campos rupestres de Goiás, sudoeste e sul de Minas Gerais. In Biodiversidade, conservação e uso sustentável da flora do Brasil (E.L. Araújo, A.N. Moura, E.V.S.B. Sampaio, L.M.S. Gestinari \& J.M.T. Carneiro, eds.) Imprensa Universitária, Recife, p.81-86.

ROSCHEL, M.B. 2000. Levantamento florístico fanerogâmico do campo rupestre da Estrada da Torre, Antônio Pereira, Ouro Preto, MG. Dissertação de mestrado, Universidade Federal do Rio de Janeiro, Rio de Janeiro.

SALISBURY, F.B. \& ROSS, C.W. 1992. Plant physiology. Wadsworth Publishing Company, Belmont.

SARTORI, A.L.B. \& TOZZI, A.M.G.A. 1998. As espécies de Machaerium Pers. (Leguminosae - Papilionoideae Dalbergieae) ocorrentes no estado de São Paulo. Revista Brasileira de Botânica 21:211-246.

VAN DER PIJL, L. 1972. Principles of dispersal in higher plants. Springer-Verlag, Berlin.

VICENT, R.C., JACOBI, C.M. \& ANTONINI, Y. 2002. Diversidade na adversidade. Ciência Hoje 31:64-67.

ZAPPI, D., LUCAS, E., STANNARD, B.L., LUGHADHA, E.N., PIRANI, J.R., QUEIROZ, L.P., ATKINS, S., HIND, N., GIULIETTI, A.M., HARLEY, R.M., MAYO, S.J. \& CARVALHO, A.M. 2002. Biodiversidade e conservação na Chapada Diamantina, Bahia: Catolés, um estudo de caso. In Biodiversidade, conservação e uso sustentável da flora do Brasil (E.L. Araújo, A.N. Moura, E.V.S.B. Sampaio, L.M.S. Gestinari \& J.M.T. Carneiro, eds.) Imprensa Universitária, Recife, p.87-89. 